\title{
Phenotypic Modulation of Cultured Primary Human Aortic Vascular Smooth Muscle Cells by Uremic Serum
}

\author{
Violeta Cazaña-Pérez ${ }^{1,2}$, Pilar Cidad ${ }^{3}$, Javier Donate-Correa ${ }^{2}$, Ernesto Martín-Núñez ${ }^{2}$, \\ José R. López-López ${ }^{3}$, M. Teresa Pérez-García ${ }^{3}$, Teresa Giraldez ${ }^{1}$, \\ Juan F. Navarro-González ${ }^{2 *}$ and Diego Alvarez de la Rosa ${ }^{\text {* }}$ \\ ' Departamento de Ciencias Médicas Básicas (Fisiología), Instituto de Tecnologías Biomédicas and Centro de \\ Investigaciones Biomédicas de Canarias, Universidad de La Laguna, Tenerife, Spain, ${ }^{2}$ Unidad de Investigación, Hospital \\ Universitario Nuestra Señora de Candelaria, Tenerife, Spain, ${ }^{3}$ Departamento de Bioquímica y Biología Molecular y Fisiología \\ e Instituto de Biología y Genética Molecular (IBGM), Universidad de Valladolid y Consejo Superior de Investigaciones \\ Científicas (CSIC), Valladolid, Spain
}

OPEN ACCESS

Edited by: Zhongkui Hong, University of South Dakota, United States

Reviewed by:

Naifeng Liu,

Southeast University, China Cynthia St. Hilaire,

University of Pittsburgh, United States

*Correspondence: Juan F. Navarro-González jnavgon@gobiernodecanarias.org Diego Alvarez de la Rosa diego.alvarez@ull.edu.es

Specialty section:

This article was submitted to

Vascular Physiology,

a section of the journal

Frontiers in Physiology

Received: 21 November 2017

Accepted: 26 January 2018

Published: 12 February 2018

Citation:

Cazaña-Pérez V, Cidad $P$ Donate-Correa J, Martín-Núñez E, López-López JR, Pérez-García MT, Giraldez T, Navarro-González JF and Alvarez de la Rosa D (2018)

Phenotypic Modulation of Cultured Primary Human Aortic Vascular Smooth Muscle Cells by Uremic

Serum. Front. Physiol. 9:89 doi: 10.3389/fphys.2018.00089
Patients with chronic kidney disease (CKD) have a markedly increased incidence of cardiovascular disease (CVD). The high concentration of circulating uremic toxins and alterations in mineral metabolism and hormone levels produce vascular wall remodeling and significant vascular damage. Medial calcification is an early vascular event in CKD patients and is associated to apoptosis or necrosis and trans-differentiation of vascular smooth muscle cells (VSMC) to an osteogenic phenotype. VSMC obtained from bovine or rat aorta and cultured in the presence of increased inorganic phosphate (Pi) have been extensively used to study these processes. In this study we used human aortic VSMC primary cultures to compare the effects of increased $\mathrm{Pi}$ to treatment with serum obtained from uremic patients. Uremic serum induced calcification, trans-differentiation and phenotypic remodeling even with normal Pi levels. In spite of similar calcification kinetics, there were fundamental differences in osteochondrogenic marker expression and alkaline phosphatase induction between $\mathrm{Pi}$ and uremic serum-treated cells. Moreover, high $\mathrm{Pi}$ induced a dramatic decrease in cell viability, while uremic serum preserved it. In summary, our data suggests that primary cultures of human VSMC treated with serum from uremic patients provides a more informative model for the study of vascular calcification secondary to CKD.

Keywords: vascular calcification, uremia, chronic kidney disease, apoptosis, osteogenic differentiation, uremic serum, inorganic phosphate, human aorta

\section{INTRODUCTION}

Chronic kidney disease (CKD) is a highly prevalent condition characterized by gradual reduction in renal function over time. CKD can arise from a variety of situations that affect the structure and function of the kidney, including advanced age, hypertension, diabetes, or cardiovascular disease (Levey and Coresh, 2012). Decreased renal function, measured as declined glomerular filtration rate (GFR), is tightly linked to increased cardiovascular risk (Tonelli and Pfeffer, 2007). During end-stage renal disease plasma accumulation of metabolites normally cleared by the 
kidney create a condition known as uremia (Meyer and Hostetter, 2007). Disorders of mineral metabolism, including alterations in the normal homeostasis of calcium, phosphorus, vitamin D, and parathyroid hormone, are an universal complication of end-stage renal disease (Meyer and Hostetter, 2007; Levey and Coresh, 2012).

Increased cardiovascular risk associated to CKD and uremia includes both cardiac and vascular components (Tonelli and Pfeffer, 2007). Hemodynamic changes and the altered metabolic state facilitate vascular wall remodeling resulting in structural and functional abnormalities. Atherosclerosis in renal patients is distinct from that in subjects without renal dysfunction, and it has been described as severe and accelerated, with increased calcification of atheroma plaques (Schwarz et al., 2000; Lu et al., 2014). In vitro experiments with arteries from uremic patients have demonstrated special characteristics of arteriosclerosis, with fibroelastic media and intima thickening, increased number of vascular smooth muscle cells (VSMC), increased extracellular matrix volume and increased calcification (Amann et al., 2003). Patients with CKD show intimal and medial calcification, with simultaneous occurrence of both processes in the same patient (Ibels et al., 1979; Schwarz et al., 2000).

Intimal calcification is associated with areas of atherosclerotic plaque, where takes place the combination of necrosis, inflammation and deposition of cholesterol, phospholipids, and lipoproteins (Boström et al., 1993; Demer, 2002). However, medial calcification is an early vascular event in CKD (Moe and Chen, 2004; Benz et al., 2017), which is directly triggered by uremia and alterations in mineral metabolism (Chen et al., 2006b). It has been demonstrated that this condition is not a passive deposition of mineral salts in the vascular wall, but rather a complex and highly regulated phenomenon by which VSMCs suffer an osteochondrogenic trans-differentiation process, eliciting expression of ossification proteins (Chen et al., 2006a) such as alkaline phosphatase, and increased expression of osteochondrogenic factors such as RUNX2 or MSX2, and chondrocyte-specific factors such as SOX9 (Giachelli, 2004).

Increased circulating phosphate concentration is a common finding in CKD patients (Lu et al., 2014). In cultured VSMC addition of phosphate to achieve levels similar to those found in $\mathrm{CKD}$ patients $(>2 \mathrm{mM})$ induce mineralization foci with characteristics similar to those found in vivo (Jono et al., 2000; Giachelli, 2004; Lu et al., 2014). It has been proposed that the $\mathrm{Na}^{+}$-dependent phosphate transporter Pit-1 allows for the accumulation of $\mathrm{Pi}$ in the cell, which in turns triggers trans-differentiation (Crouthamel et al., 2013). However, Pi transport in VSMC is saturated under normal conditions and Pit-1 expression does not appear to be increased under hyperphosphatemia, indicating that other factors may provide additional signals to induce osteochondrogenic differentiation and calcification (Villa-Bellosta et al., 2007; Villa-Bellosta and Sorribas, 2009).

Many aspects regarding the complex process of vascular calcification and phenotypic remodeling secondary to CKD and uremia remain unanswered. The process has been studied using different in vitro models, including intact vessels (Shroff et al., 2008), aortic rings (Lomashvili et al., 2004; Sonou et al., 2015), or dispersed VSMC, mainly obtained from bovine or rat thoracic aorta (Chen et al., 2006a; Villa-Bellosta et al., 2007; Hortells et al., 2015). In spite of the limitations associated with cultured VSMC, such as the lack of extracellular elastin fibers (Lin et al., 2011) and the diversity of phenotypes that can co-exist in culture (Patel et al., 2016), this model has been extensively used to study vascular calcification. Particularly, the fact that increased $\mathrm{Pi}$ in the culture medium induces mineralization and increases osteoblastic markers makes the VSMC model very popular in calcification research. However, it has been demonstrated that small changes in culture conditions can produce significantly different results (Hortells et al., 2015). In addition, it has now become clear that even though $\mathrm{Pi}$ is a significant player in the process, other metabolites present in uremic serum are involved in the structural and functional alteration of the vascular wall in CKD (Smith, 2016; Yamada and Giachelli, 2017). Finally, species-specific differences may difficult the reproducibility of observations in the field (Scialla et al., 2013).

In this study we used human aortic VSMC primary cultures treated with serum from uremic patients or healthy individuals, and compared them with cultures with increased $\mathrm{Pi}$ concentrations to study calcification and phenotypic remodeling. Our results showed that uremic serum is able to induce calcification, trans-differentiation and phenotypic remodeling even with normal Pi levels. Even though the kinetic of calcification induced by serum was similar to that observed with increased $\mathrm{Pi}$, analysis of molecular markers revealed fundamental differences in osteochondrogenic marker expression and alkaline phosphatase induction. Moreover, high $\mathrm{Pi}$ induced a dramatic decrease in cell viability, while human uremic serum preserved it, with a modest increase in apoptosis but a drastic change in phenotype.

\section{MATERIALS AND METHODS}

\section{Ethical Approval, Patient Selection, and Serum Biochemistry}

Patient and healthy individuals were recruited at the Nephrology Service, Hospital Universitario Nuestra Señora de Candelaria (Tenerife, Spain) after approval by the Hospital Ethics Committee. All subjects gave informed consent to participate. The studies conformed to the standards set by the latest revision of the Declaration of Helsinki.

Control serum samples were obtained from 16 healthy donors and uremic serum samples were obtained from 16 patients with stage $5 \mathrm{D}$ CKD (estimated GFR $\leq 15 \mathrm{ml} / \mathrm{min} / 1,73 \mathrm{~m}^{2}$ ). Characteristics and biochemical parameters of healthy (control) and uremic serum samples are summarized in Table 1. All participants were older than 18 years old. Exclusion criteria included pregnancy, current smoking habit, alcohol dependence or drug abuse, history of immunologic, or tumoral disease, an acute inflammatory or infectious episode in the previous month, hepatitis B, C, or HIV positivity, prior transplantation, and immunotherapy, immunosuppressive, anti-inflammatory, or steroid treatment. Blood samples were obtained after an $8 \mathrm{~h}$ fasting period by venipuncture. After centrifugation aliquots 
TABLE 1 | Characteristics and biochemical parameters of healthy (control) and uremic serum.

\begin{tabular}{lccc}
\hline & Control serum & Uremic serum & p-value \\
\hline Number of patients & 16 & 16 & - \\
Age (years) & $39-58$ & $25-45$ & \\
Gender (male;female) & $6 ; 10$ & $8 ; 8$ & - \\
Albumin (mg/dl) & $4.1 \pm 0.07$ & $3.81 \pm 0.1$ & 0.005 \\
Urea (mg/dl) & $33.5 \pm 1.8$ & $88.56 \pm 4.2$ & $<0.0001$ \\
Creatinine (mg/dl) & $1.01 \pm 0.0$ & $5.38 \pm 0.2$ & $<0.0001$ \\
Inorganic phosphate (mg/dl) & $3.57 \pm 0.1$ & $5.84 \pm 0.3$ & $<0.0001$ \\
Ca ${ }^{2+}(\mathrm{mg} / \mathrm{dl})$ & $9.82 \pm 0.1$ & $8.83 \pm 0.2$ & 0.011 \\
K+ (nmol/l) & $4.37 \pm 0.1$ & $5.26 \pm 0.2$ & $<0.0001$ \\
Vitamin D (ng/ml) & $47.63 \pm 3.54$ & $19.19 \pm 1.19$ & $<0.0001$ \\
Parathyroid hormone (pg/ml) & $40.86 \pm 2,01$ & $505.9 \pm 57.25$ & $<0.0001$ \\
Alkaline phosphatase (U/l) & $73.38 \pm 5.62$ & $81.38 \pm 4.57$ & 0.278 \\
\hline
\end{tabular}

Biochemical parameters are given as average $\pm S E$ in the indicated units. Statistical analysis was performed using Student's t-test.

of individual serum samples were saved for biochemical determinations and the rest were pooled, aliquoted and stored at $-80^{\circ} \mathrm{C}$ until use. Each sample was thawed only once.

Serum biochemistry values are shown in Table $\mathbf{1}$ and are consistent with the expected differences between control and uremic serum for this stage of disease.

\section{Primary Human Aorta Vascular Smooth Muscle Cell Culture and Treatments}

Primary human aorta vascular smooth muscle cells (HASMC) were isolated by ScienCell Research Laboratories, Inc. (Carlsbad, CA) and purchased through Innoprot (Derio, Spain). Primary HASMC were cultured according to the manufacturer's instructions. Briefly, cells were cultured at $37^{\circ} \mathrm{C}$ in a $5 \%$ $\mathrm{CO}_{2}$ atmosphere saturated with water. Culture medium was high glucose Dulbecco's Modified Eagles Medium (DMEM) supplemented with $10 \%$ fetal bovine serum, smooth muscle cellspecific growth factors (Innoprot), penicillin/streptomycin and $0.2 \%$ MycoZap $^{\mathrm{TM}}$ (Lonza) to prevent mycoplasma contamination. Culture surfaces were pre-coated with a solution containing $1 \mathrm{mg} / \mathrm{ml}$ fibronectin in $0.2 \%$ gelatin (SigmaAldrich). Medium was replaced every $48 \mathrm{~h}$ until cells reached $\sim 50 \%$ confluence. Afterwards medium was replaced daily and cells were subcultured when they reached $80-90 \%$ confluence. Once cells were confluent they were transferred to experimental medium consisting on culture medium supplemented with $20 \%$ of control or uremic human serum or DMEM with $\mathrm{CaCl}_{2}$, $\mathrm{NaH}_{2} \mathrm{PO}_{4}$, and $\mathrm{Na}_{2} \mathrm{HPO}_{4}$ to reach a final concentration of $2.5 \mathrm{mM}$ inorganic phosphate $(\mathrm{Pi})$ and $2 \mathrm{mM}$ calcium in the medium. All experiments were performed using cells between passage 3 and 5 .

\section{Calcification}

Deposition of calcium phosphate crystals was assessed by alizarin red staining. Briefly, cells were seeded in 96-well plates and after reaching confluence were transferred to experimental media containing either control or uremic serum. Cells were then fixed for $30 \mathrm{~min}$ with $10 \%$ formalin. Cells were then washed and stained with $1 \%$ alizarin red (Sigma-Aldrich), which chelates calcium forming a red precipitate. The monolayers were washed twice with $\mathrm{dH}_{2} \mathrm{O}$ while shaking to remove the excess of dye. The plate was then immersed in $60 \%$ isopropanol and later in $100 \%$ isopropanol for $1 \mathrm{~min}$. To quantify the amount of precipitate formed cells were dissolved with $10 \%$ acetic acid and the alizarin red absorption was measured at $450 \mathrm{~nm}$ in a plate spectrophotometer. Protein content was measured for each lysate using the bicinchoninic acid method (BCA assay kit, SigmaAldrich) following the manufacturer instructions.

\section{Alkaline Phosphatase Activity}

Alkaline phosphatase activity, a marker for osteogenic activity, was quantified using a colorimetric assay in cell lysates. Briefly, cells were treated as described above, washed with PBS and lysed in a buffer containing $50 \mathrm{mM}$ Tris pH6.8, 1\% Triton X-100 and $2 \mathrm{mM} \mathrm{MgCl}_{2}$. After $30 \mathrm{~min}$ incubation, lysates were cleared by centrifugations and supernatants were used to determine enzyme activity. The reaction mixture $(50 \mu \mathrm{l})$ included $50 \mathrm{mM}$ p-nitrophenyl phosphate (pNPP, Sigma-Aldrich) prepared in 2amino-2-methyl-1-propanol (Sigma-Aldrich). After $15 \mathrm{~min}$ of incubation at $37^{\circ} \mathrm{C}$ in darkness the reaction was stopped by addition of $3 \mathrm{~N} \mathrm{NaOH}$. Conversion of pNPP to p-nitrophenol was quantified by reading the absorbance at $405 \mathrm{~nm}$ and normalization to total protein content measured by the BCA procedure (see above).

\section{Cell Viability}

HASMC viability was assessed using a colorimetric assay based on the reduction of the yellow tetrazolium salt XTT (2,3-bis(2-methoxy-4-nitro-5-sulfophenyl)-5[(phenylamino)carbonyl $]-2 \mathrm{H}$ - tetrazolium hydroxide) to an orange water-soluble formazan dye that only occurs in cells that are metabolically active (Scudiero et al., 1988). Viability was measured after 2, 5, or 10 days in experimental media using a commercial kit (Cell Proliferation Kit XTT, Applichem GmbH). Formazan dye concentration was measured by absorption spectrophotometry at $450 \mathrm{~nm}$, repeating the measurement at $630 \mathrm{~nm}$ to subtract non-specific absorption. Viability is expressed as percentage of the value obtained under control conditions. HASMC cell viability was further studied by Trypan Blue exclusion and direct cell counting in a Neubauer chamber.

\section{Cell Proliferation}

HASMC proliferation was assessed by 5-ethynyl-2' -deoxyuridine (EdU) incorporation using a commercially available kit (Click$\mathrm{iT}^{\circledR}$ EdU Imaging Kit, ThermoFisher Scientific) as we have described previously (Cidad et al., 2015). Briefly, cells were seeded at a density of 15,000 cells $/ \mathrm{cm}^{2}$. One day after seeding cells were transferred to experimental media with control or uremic serum and incubated for $48 \mathrm{~h}$. EdU was then added at a concentration of $10 \mu \mathrm{M}$ and cells were incubated for $1,6,12,24$, or $48 \mathrm{~h}$ before fixation with $4 \%$ formaldehyde. Fluorescent staining of EdU with Alexa 488 fluorophore followed the manufacturer instructions. Cell nuclei were counterstained using Hoechst 33342 (ThermoFisher Scientific). Preparations 
were mounted using Mowiol (Calbiochem) containing $0.1 \%$ Diazobicyclo-octane (Aldrich) as anti-fading agent. Cells were examined under a Leica TCS SP8 confocal microscope. For quantitation, 15 independent fields were randomly selected and the proportion of cells with EdU positive nuclei was scored.

\section{Apoptosis}

Quantification of apoptosis was performed by measuring cell surface accumulation of phosphatidylserine (PS) via binding of annexin-V-FITC (Santa Cruz Biotechnology) using flow cytometry. Briefly, treated cells were washed with PBS, centrifuged and resuspended in annexin- $\mathrm{V}$ binding buffer (in mM: 10 HEPES, pH 7.4; $140 \mathrm{NaCl} ; 2.5 \mathrm{CaCl}_{2}$ ) supplemented with $0.2 \mu \mathrm{g} / \mu \mathrm{l}$ annexin-V-FITC. After $15 \mathrm{~min}$ of incubation cell were centrifuged and resuspended in the same buffer containing $0.6 \mu \mathrm{g} / \mathrm{ml}$ of propidium iodide (PI). Samples were analyzed in duplicate $(15,000$ cells/condition) in a MACSQuant Analyzer 10 apparatus (Miltenyi Biotec) using $488 \mathrm{~nm}$ light for excitation. FITC signal was detected at $518 \mathrm{~nm}$ and PI at $620 \mathrm{~nm}$. Data are presented as percentage of cells undergoing early apoptosis (annexin-V-positive, PI-negative cells) or late apoptosis (annexin-V and PI-positive cells).

\section{Cell Migration Assays}

To quantify the ability of HASMC to migrate in culture we used cultures grown to confluence in $35 \mathrm{~mm}$ dishes containing a silicon insert that forms two chambers with $\sim 4 \times 10^{4}$ cells each (Ibidi, GmbH). After $48 \mathrm{~h}$ in the presence of control or uremic serum, the silicon insert is removed and culture medium is changed to serum-free DMEM to prevent cell proliferation. Cells were then incubated for $24,48,72$, or $120 \mathrm{~h}$. Images were analyzed using ImageJ software (National Institutes of Health, Bethesda, MD) freely available at http://imagej.nih.gov/ij/ (Schneider et al., 2012). Migration is expressed as percentage of the initial empty area that remains free of cells.

\section{Quantification of Gene Expression}

Total HASMC RNA was purified using a commercially available kit (Total RNA Spin Plus Kit, REAL, Valencia, Spain). Concentration and purity of RNA was estimated by using absorption spectrophotometry in a Nanodrop 2000 apparatus (Thermo Scientific). cDNA was synthesized using a commercial kit (iScriptTM cDNA Synthesis Kit, Bio-Rad) following the manufacturer instructions. Quantification of gene expression was performed using commercial Taqman ${ }^{\circledR}$ probes and a TaqMan ${ }^{\circledR}$ 2X Universal PCR Master Mix (Applied Biosystems, CA) in a CFX96 Touch $^{\text {TM }}$ Real-Time PCR Detection System (Bio-Rad). Each TaqMan probe was tested for linearity and efficiency of amplification, which was always between 90 and $110 \%$. Normalization and relative quantification was performed with the $\Delta \Delta$ Ct method (Schmittgen and Livak, 2008), using glyceraldehyde-3-phosphate dehydrogenase (GAPDH) as housekeeping gene.

\section{Immunocytochemistry}

Indirect immunofluorescence staining was performed as previously described (Coric et al., 2004). Expression of smooth muscle actin ( $\alpha$ SMA) was detected using mouse monoclonal antibody 1A4 (Sigma Aldrich) at 1:400 dilution. After staining cell were mounted in Mowiol medium containing $1 \mu \mathrm{g} / \mathrm{ml}$ DAPI to counterstain cell nuclei medium and examined under a Leica TCS SP8 confocal microscope.

\section{Intracellular Calcium Concentration Measurements}

Free intracellular $\mathrm{Ca}^{2+}$ concentration was measured using the fluorescent probe fluo-4. Cells were loaded with the probe using its acetoxymethyl esther (fluo-4/AM, Molecular Probes). Briefly, HASMC were seeded on glass coverslips and treated as described above. After washing in serum-free medium, cells were loaded with fluo-4/AM for $30 \mathrm{~min}$ at room temperature in the dark. Cells were then washed with complete medium to eliminate unincorporated probe and incubated for 10 more minutes at room temperature to allow for ester hydrolysis. Coverslips were then placed in a perfusion chamber in an inverted fluorescence microscope (Olympus IX70). A field of interest with several cells was selected and perfusion was started with extracellular solution (in mM: $10 \mathrm{HEPES}, 141 \mathrm{NaCl}, 4.7 \mathrm{KCl}, 1.2 \mathrm{MgCl}_{2}, 1.8 \mathrm{CaCl}_{2}$, 10 glucose, $\mathrm{pH}$ 7.4) and kept for $15 \mathrm{~min}$ in the dark to allow cells to stabilize. Experiments were performed using excitation light at $480 \mathrm{~nm}$ and recording through a dichroic mirror at 505 and an emission filter at $520 \mathrm{~nm}$. Cells were treated with $10 \mu \mathrm{M}$ angiotensin II to induce receptor-mediated intracellular $\mathrm{Ca}^{2+}$ transients. Cells were then perfused with $\mathrm{Ca}^{2+}$-free extracellular solution and treated with cyclopiazonic acid $(10 \mu \mathrm{M})$ to inhibit sarco/endoplasmic reticulum $\mathrm{Ca}^{2+}$-ATPase (SERCA), emptying intracellular $\mathrm{Ca}^{2+}$ stores. At the end of experiment we added $10 \mu \mathrm{M}$ ionomycin to make cells permeant to $\mathrm{Ca}^{2+}$ and obtain the maximum fluorescent signal $\left(\mathrm{F}_{\max }\right)$, which was used to normalize each experiment. Free $\mathrm{Ca}^{2+}$ concentration was calculated using the following equation:

$$
\left[C a^{2+}\right]=300 \times\left[\frac{\left(\frac{F 480}{F 480_{\max }}\right)}{\left(\frac{1-F 480}{F 480_{\max }}\right)}\right]
$$

where $300(\mathrm{nM})$ is the Kd of Fluo-4 and F480 and F480 max are the fluorescence intensities of the stimulus and ionomycin respectively. Data recording and analysis was performed using Imaging Workbench 4.0 (Axon Instruments) and MatLab software, respectively.

\section{Statistical Analysis}

Statistical analysis was performed using Prism5 (GraphPad). Data are presented as average \pm SE. Unless stated otherwise, each experiment was repeated at least three times and was performed in triplicate. Comparison between three or more groups was performed using one-way ANOVA followed by Tukey's post-hoc test. Comparison between two groups was performed using Student's $t$-test. Statistical significance was set at $p<0.05$. 


\section{RESULTS}

\section{HASMC Develop Calcification in Response to Uremic Serum or Increased Extracellular Phosphate}

We first tested the ability of uremic serum to induce calcification in primary cultures of human aortic vascular smooth muscle cells (HASMC). As a positive control, we also treated the cells with DMEM medium supplemented to bring $\mathrm{Pi}$ and
$\mathrm{Ca}^{2+}$ concentration to 2.5 and $2 \mathrm{mM}$, respectively, a condition classically used to elicit calcification in vitro. Alizarin red staining revealed that increased extracellular $\mathrm{Pi}$ and $\mathrm{Ca}^{2+}$ induced extensive deposition of $\mathrm{Ca}^{2+}$-containing crystals, which are absent under normal conditions (Figure 1A). Colorimetric quantification of $\mathrm{Ca}^{2+}$ content revealed up to seven-fold accumulation after 3 days of treatment (Figure 1C). When HASMC where cultured with DMEM medium supplemented with human uremic serum they developed a similar pattern
A
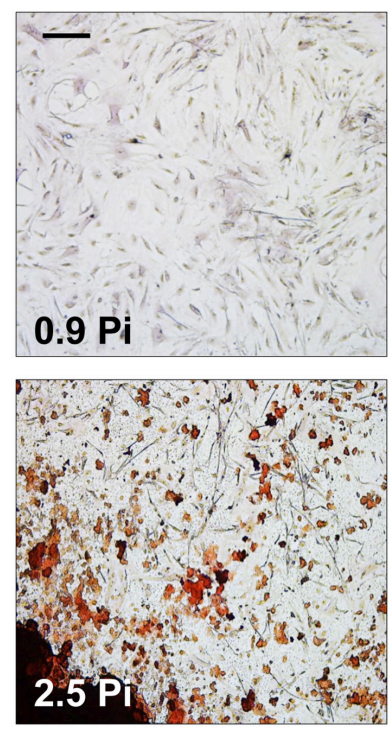

B
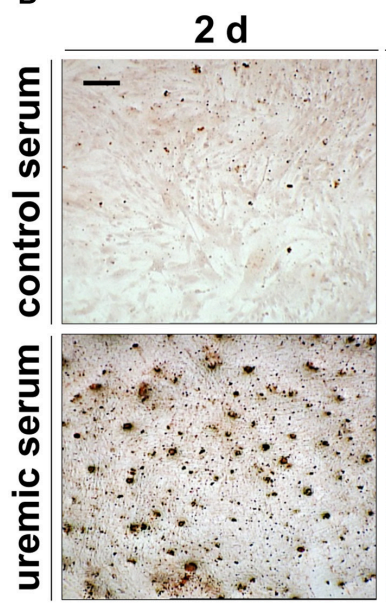

C

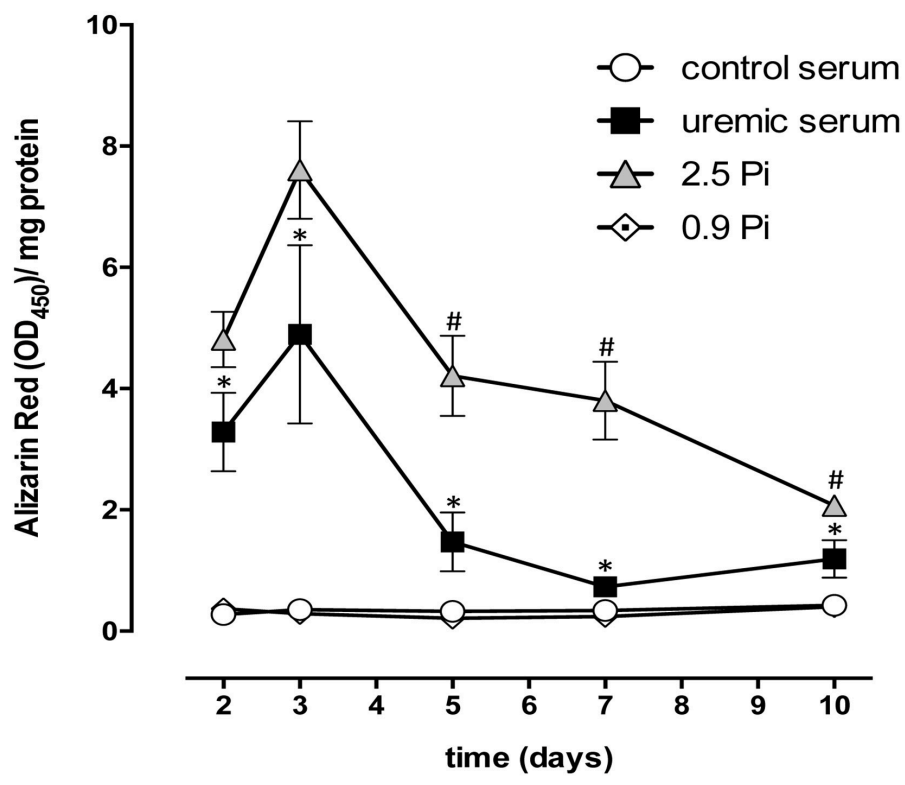

$5 d$

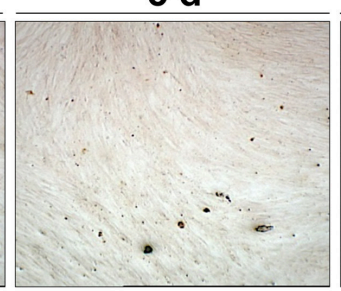

$7 \mathrm{~d}$

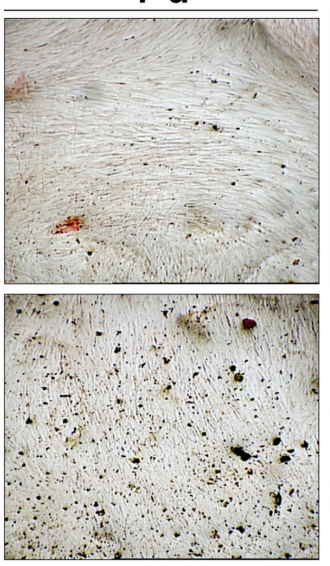

$10 d$

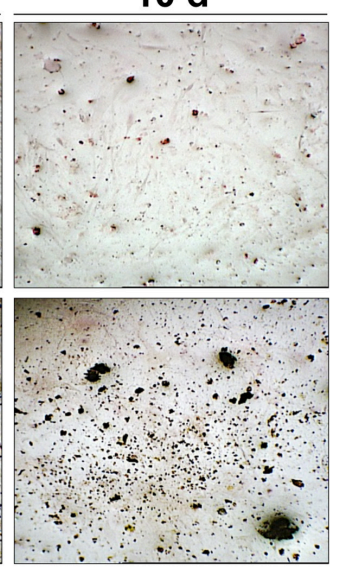

FIGURE 1 | Quantification and time-course of calcification in HASMCs treated with high phosphate or serum from uremic patients. Cells were incubated for the indicated time in DMEM with the standard amount of inorganic phosphate (0.9 Pi), increased amount of $\mathrm{Pi}$ and $\mathrm{Ca}^{2+}(2.5 \mathrm{Pi})$, or in DMEM supplemented with $20 \%$ control or uremic serum. (A) Representative micrographs of HASMCs cultured in DMEM with $0.9 \mathrm{Pi}$ or increased amount of inorganic phosphate and calcium (2.5 Pi) and stained with Alizarin red. Bar, $150 \mu \mathrm{m}$. (B) Representative micrographs of HASMCs cultured in DMEM supplemented with control or uremic serum for the indicated amount of times (values in days) and stained with Alizarin red. Bar, $110 \mu \mathrm{m}$. (C) Quantitative analysis of calcium phosphate deposition by Alizarin Red staining; each point represents the average \pm SE absorbance at $450 \mathrm{~nm}$ for the indicated day of treatment (three independent experiments, with 4 replicas per condition in each experiment). Values were compared using a one-way ANOVA followed by Tukey's multiple comparisons test. *Significant vs. control serum; \# significant vs. uremic serum. 
of calcium deposition, which peaked after 3 days of treatment (Figures 1B,C).

\section{Molecular Markers of Trans-Differentiation Are Differentially Regulated by $\mathrm{Pi}$ and Uremic Serum}

The previous experiment demonstrates that hyperphosphatemia and exposure to uremic serum produce similar calcification in HASMC. However, calcification associated to CKD involves HASMC trans-differentiation to an osteochondrogenic lineage. To investigate whether both calcification models produce similar trans-differentiation we examined the expression of molecular markers associated to this process. We first analyzed the expression of homeobox protein MSX2, a component of the bone morphogenetic protein pathway that promotes cardiovascular calcification (Tyson et al., 2003; Shimizu et al., 2012). Both Pi and uremic serum exposure induced the expression of MSX2 throughout the treatment (Figure 2A), with a stronger effect induced by the former. VSMC conversion to chondrocytes has also been implicated in medial calcification in uremic rats (Neven et al., 2010). Therefore, we quantified the expression of SOX9, a master regulator of chondrocyte differentiation (Liu C.F. et al., 2016). SOX9 expression followed a pattern similar to MSX2, with both stimuli enhancing expression throughout the treatment, with a more marked induction produced by $\mathrm{Pi}$ (Figure 2B). Runt-related transcription factor 2 (RUNX2), a transcription factor that is essential for osteochondrogenic differentiation, was significantly enhanced throughout the treatment with uremic serum (Figure 2C). Surprisingly, hyperphosphatemia repressed the expression of RUNX2 (Figure 2C), suggesting that this model produces a pattern of HASMC trans-differentiation that is significantly different from that induced by uremia. Given that increased RUNX2 expression is a transient early event in osteoblast differentiation, we also compared its level to expression at day 0 of the experiment (Figure 2D). It can be observed that control human serum increases RUNX2 expression, but to a lower extent than uremic serum.

The result obtained with RUNX2 expression prompted us to investigate further markers involved in osteochondrogenic differentiation. One such marker, the $\mathrm{Na}^{+} / \mathrm{Pi}$ co-transporter Pit1 has been proposed to play an important functional role in this process in a rat model of uremia (Mizobuchi et al., 2006) and in phosphate-induced calcification of cultured human VSMC (Li et al., 2006). Consistently with this report, we found induction of Pit-1 mRNA in HASMC exposed to hyperphosphatemia at every time point examined, starting after 2 days of treatment (Figure 2E). In contrast, treatment with uremic serum only induced increased Pit-1 expression after 7 days, which does not correlate with the start of calcification. This result also suggests that the trans-differentiation mechanisms induced by hyperphosphatemia and uremia may be fundamentally different.

An important component modulating tissue biomineralization is the expression of calcification inhibitors such as osteopontin (OPN, also known as secreted phosphoprotein 1, or SPP1), which acts by regulating crystal growth (Wada et al., 1999; Lomashvili et al., 2004). Upregulated expression of OPN has been demonstrated at sites of ectopic calcification, including the vascular wall (Abedin et al., 2004). We tested OPN mRNA expression in HASMC and found a potent initial up-regulation both by uremic serum or high extracellular phosphate. However, uremic serum effects OPN were mostly transient, while increased extracellular phosphate maintained a high level of OPN expression throughout the experiment (Figure 2F).

One of the most relevant markers of osteoblast activity is alkaline phosphatase (ALP). We studied ALP expression and function in control HASMC or cells treated with uremic serum or exposed to increased Pi. Surprisingly, exposure to high extracellular Pi potently repressed ALP expression and activity (Figures 3A,B). In contrast, uremic serum did not alter ALP expression during the first 5 days of the experiment, but produced a significant increase in mRNA abundance in cells exposed to uremia for 7 days (Figure 3A). Most importantly, ALP activity was potently repressed by Pi but significantly increased by uremic serum for the duration of the experiment (Figure 3B).

\section{High Phosphate Dramatically Decreases HASMC Viability}

In order to compare the effect of high Pi with uremic serum on cell viability we tested HASMC ability to reduce a tetrazolium salt (XTT) in the presence of an electron-coupling reagent, to produce a water-soluble formazan dye. This reaction depends on $\mathrm{NAD}(\mathrm{P}) \mathrm{H}$, which in turn depends on cellular metabolic activity. XTT reduction was measured at 2, 5, and 10 days of treatment. In both control and uremic conditions the amount of XTT, which is proportional to cell proliferation and viability, increased over time (Figure 4). Uremic serum induced a small but significant decrease in XTT reduction, which averaged 9-13\% less than in control cells, a difference that tended to decrease over time (Figure 4). In contrast, high Pi produced a dramatic decrease in cell viability, which reached a $90 \%$ decline during the course of the experiment (Figure 4). Together with the data examining the expression of trans-differentiation markers, these results indicate that exposing HASMC to high phosphate medium not only does not reproduce the expected differentiation process, but also decreases massively cell viability. This strongly indicates that using high phosphate as a model for uremic calcification is inadequate. Since XTT reduction depends both on cellular metabolic activity, which is related to cell viability, and also on the number of cells present on the culture, we directly examined whether uremic conditions alter cell proliferation and decrease the overall number of living cells in culture. To that end we measured the total number of viable HASMC in culture by counting cells able to exclude Trypan Blue. Total number of cells in culture did not change until after 5 days of treatment with uremic serum (Figure 5A). When only viable cells are taken into account, uremia induced a slight decrease in every time point tested (Figure 5B). Experiments using Pi treatment were difficult to interpret, most likely due to the dramatic decrease in cell viability detected under this condition. It is worth noting that the decrease in viable cells induced by uremic serum and assessed by Trypan Blue exclusion ( $\sim 50 \%)$ is much higher than 
A

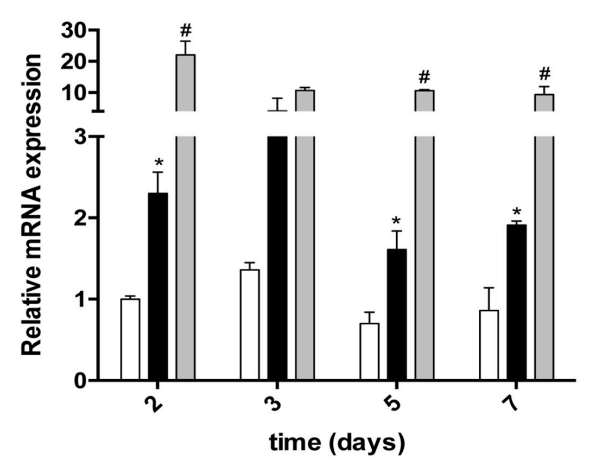

C

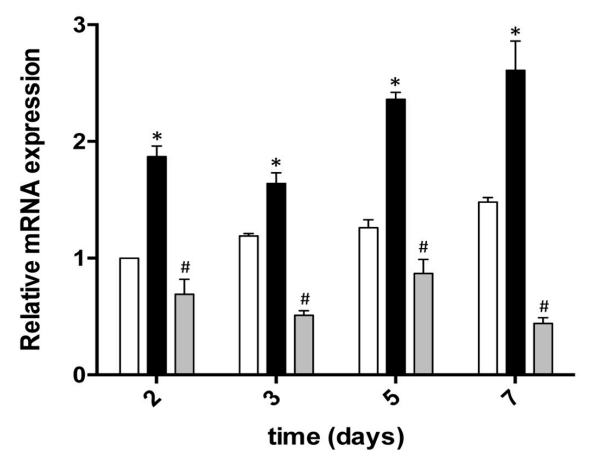

E

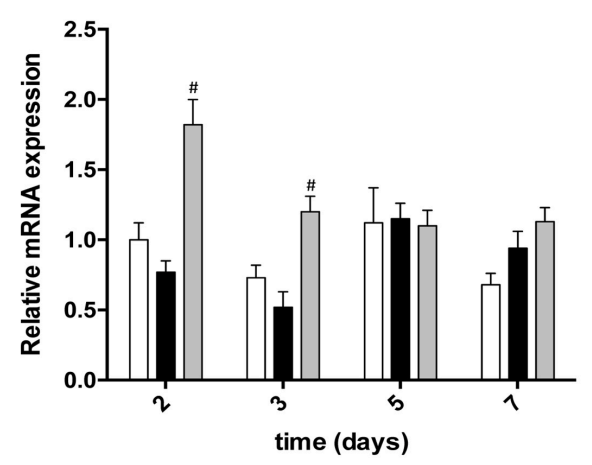

B

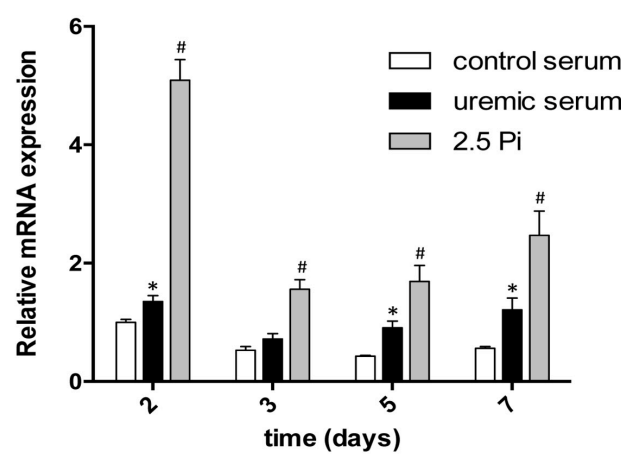

D

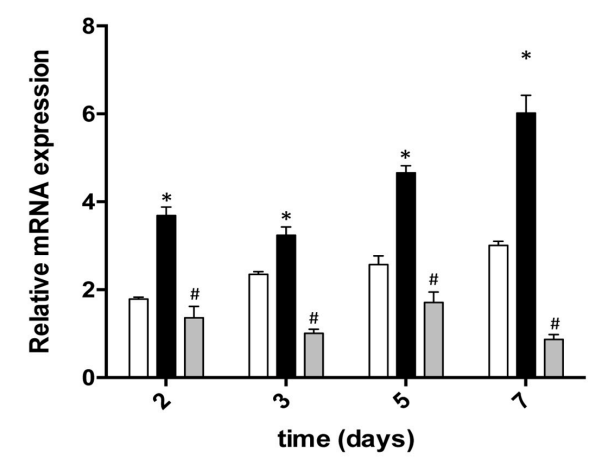

F

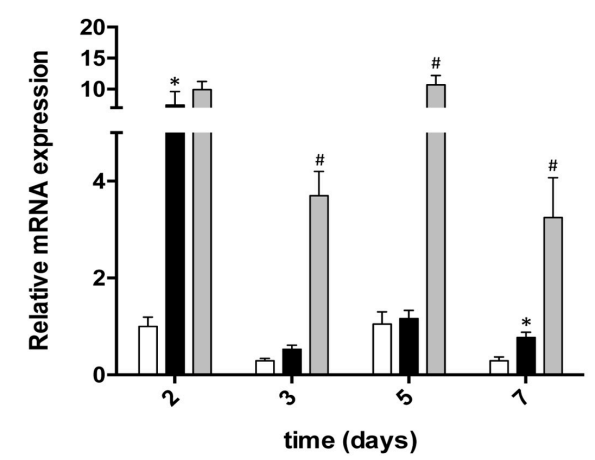

FIGURE 2 | Differential modulation of osteochondrogenic differentiation marker expression in HAMSC treated with high phosphate or uremic serum. Cells were incubated for the indicated times in DMEM with increased $\mathrm{Pi}$ and $\mathrm{Ca}^{2+}(2.5 \mathrm{Pi})$ or in DMEM supplemented with $20 \%$ of control or uremic serum. Expression of the indicated osteochondrogenic markers (A-F; each individual marker is identified above the corresponding graph) was evaluated with qPCR. The expression of target genes was normalized to GAPDH. Results are presented as the mean $\pm \mathrm{SE}(N=3)$ normalized to expression under control serum conditions on day 2, except for (D), where data are normalized to day 0 . Values were compared using a one-way ANOVA followed by Tukey's multiple comparisons test. *Significant change vs. control serum; \# significant change vs. uremic serum.

that estimated by XTT reduction (Figure 4). This result suggests that in the presence of uremic serum cells proliferate at a lower rate but may have a higher than normal metabolic activity, as assessed by XTT reduction, which in turn depends on $\mathrm{NAD}(\mathrm{P}) \mathrm{H}$ availability.

To directly assess HASMC proliferation rate we measured EdU incorporation as readout of DNA synthesis (Figure $5 \mathrm{C}$ ).
EdU incorporation progressively increased with time, as expected (Figure 5D). Uremic serum did not have a significant effect during the first day of treatment, but decreased EdU incorporation by $15 \%$ after 2 days.

Taken together, the data suggests an early decrease in cell viability, followed by slightly decreased proliferation by day 2 , which may be accompanied by higher metabolic activity in 


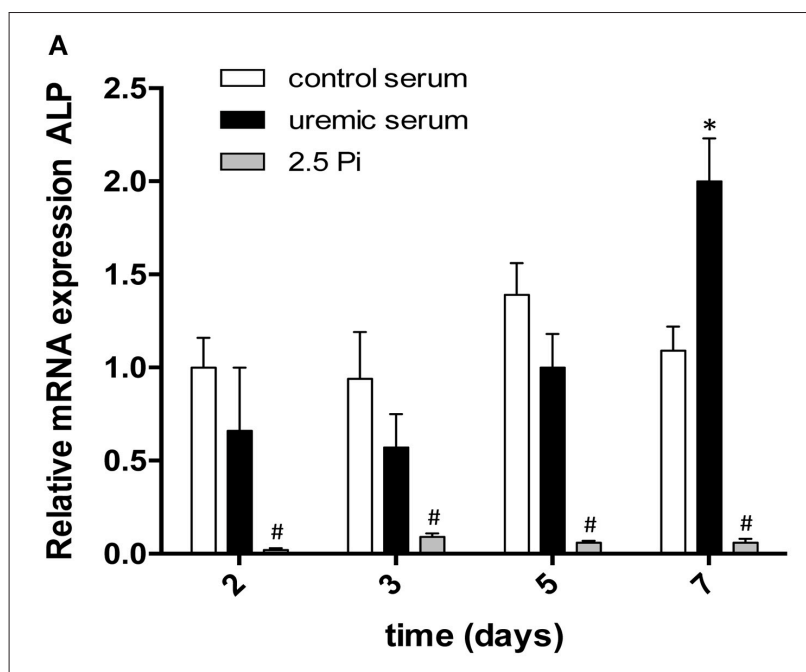

B

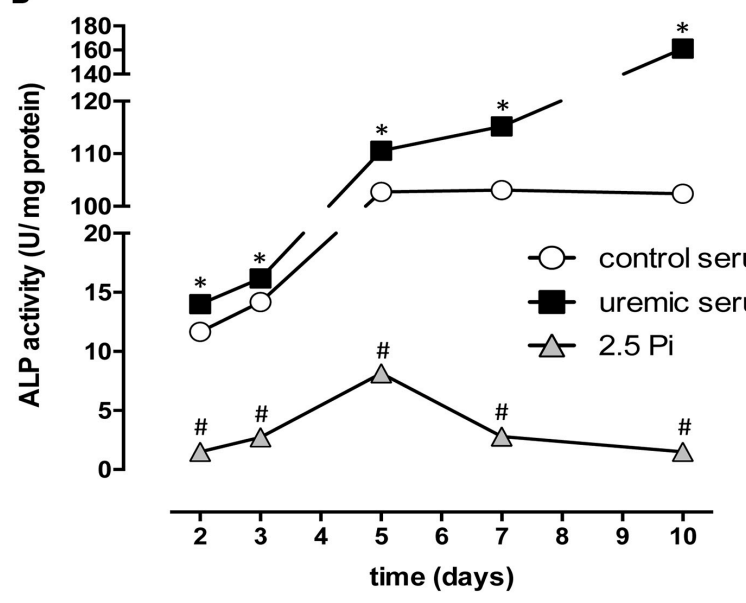

FIGURE 3 | Expression and activity of alkaline phosphatase are increased by uremic serum but potently reduced by high phosphate. (A) Alkaline phosphatase (ALP) mRNA expression in HASMC incubated in DMEM for the indicated amount of time with increased $\mathrm{Pi}$ and $\mathrm{Ca}^{2+}(2.5 \mathrm{Pi})$, or in DMEM supplemented with $20 \%$ control or uremic serum. The expression of ALP gene was normalized to GAPDH. Results are presented as the mean $\pm \mathrm{SE}(N=3)$; *significant vs. control serum; \# significant vs. uremic serum. (B) Intracellular ALP activity measured using a colorimetric assay. Each measurement was normalized for total protein. Data are shown as mean $\pm \mathrm{SE}(N=3)$. Values were compared using a one-way ANOVA followed by Tukey's multiple comparisons test. *Significant vs. control serum; \# significant vs. uremic serum.

the surviving cells. To confirm this observation we directly assessed the occurrence of apoptosis in control, Pi-treated or uremic serum-treated HASMC cultures using flow cytometry in cells stained with annexin $\mathrm{V}$ and propidium iodide (PI). Annexin V-positive and PI-negative staining was considered a sign of early apoptosis, while positive staining for both markers was considered a sign of late apoptosis/necrosis. After 1 daytreatment with uremic serum, there was an overall increase in apoptotic cells in culture from $\sim 13$ to $18 \%$. This increase was mostly due to enhanced early apoptosis, which changed from $\sim 10$ to $15 \%$ (Figure $5 \mathrm{E}$ ). This is in agreement with the data

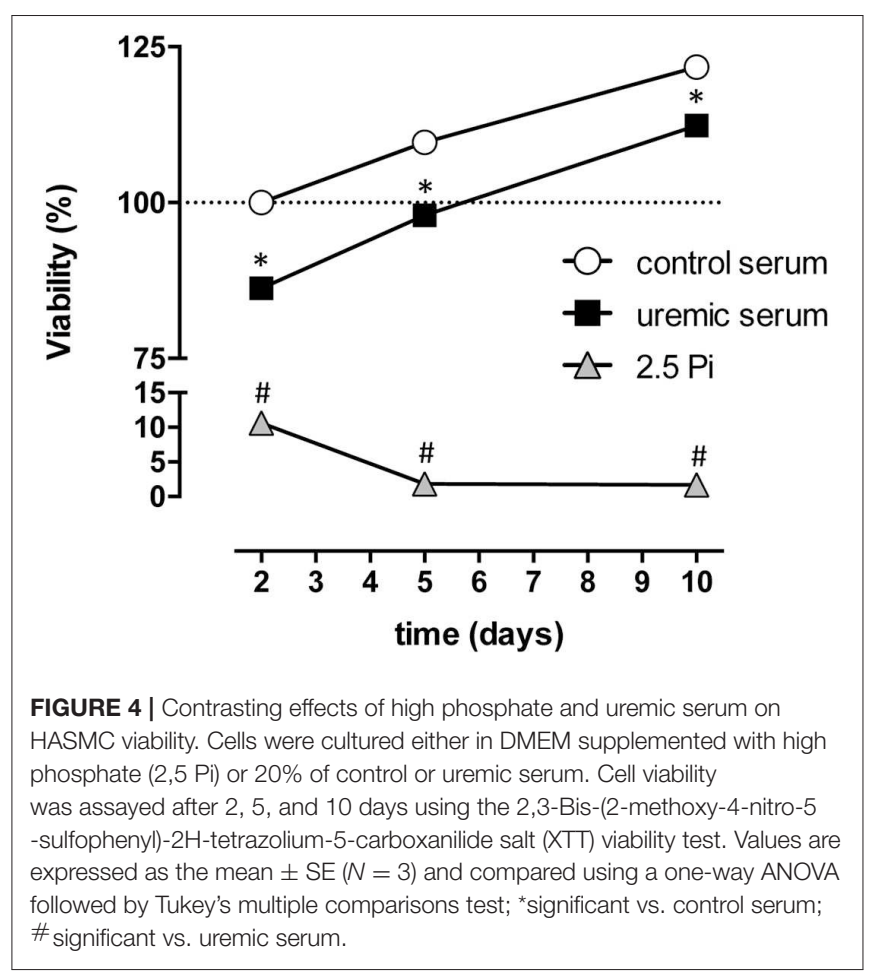

obtained with our proliferation measurements, which suggest an early decrease in cell viability. After 2 days in uremic serum, HASMC did not show any significant difference in early or late apoptosis when compared to control cells (Figure 5E), again confirming the proliferation data. By day 5 of treatment apoptosis is generally low in both conditions, although slightly increased in uremia-exposed cells (Figure 5E). Consistently with the dramatic loss of cell viability detected with $\mathrm{Pi}$, this treatment produced a very large increase in cell apoptosis starting as soon as day 1 (Figure 5E). Therefore, the rest of our study focused on treating cells with uremic serum.

\section{Uremic Serum Decreases Smooth Muscle Actin Expression and Impairs Calcium Handling in HASMC}

In order to examine the consequences of uremic serum on the functional properties of HASMC, we first measured expression of smooth muscle $\alpha$-actin, the actin isoform characteristically expressed in VSMC (Skalli et al., 1986). Immunocytochemistry revealed robust expression in control cells, with the characteristic fibrilar pattern (Figure 6A). Uremic serum produced a marked decrease in smooth muscle $\alpha$-actin expression that was already apparent after 3 days of treatment (Figures 6A,B).

Given that the response of VSMCs to physiological stimuli depends on a rise in cytosolic $\mathrm{Ca}^{2+}$, we next examined the effect of uremia on $\mathrm{Ca}^{2+}$ handling. Average basal cytosolic $\mathrm{Ca}^{2+}$ concentration decreased after treatment with uremic serum (in nM: $133.0 \pm 6.3$ in control cells, $103.7 \pm 5.2$ in uremiaexposed cells; Figure 6C). Response to a known vasoconstrictor agent such as angiotensin II was blunted in uremic cells 


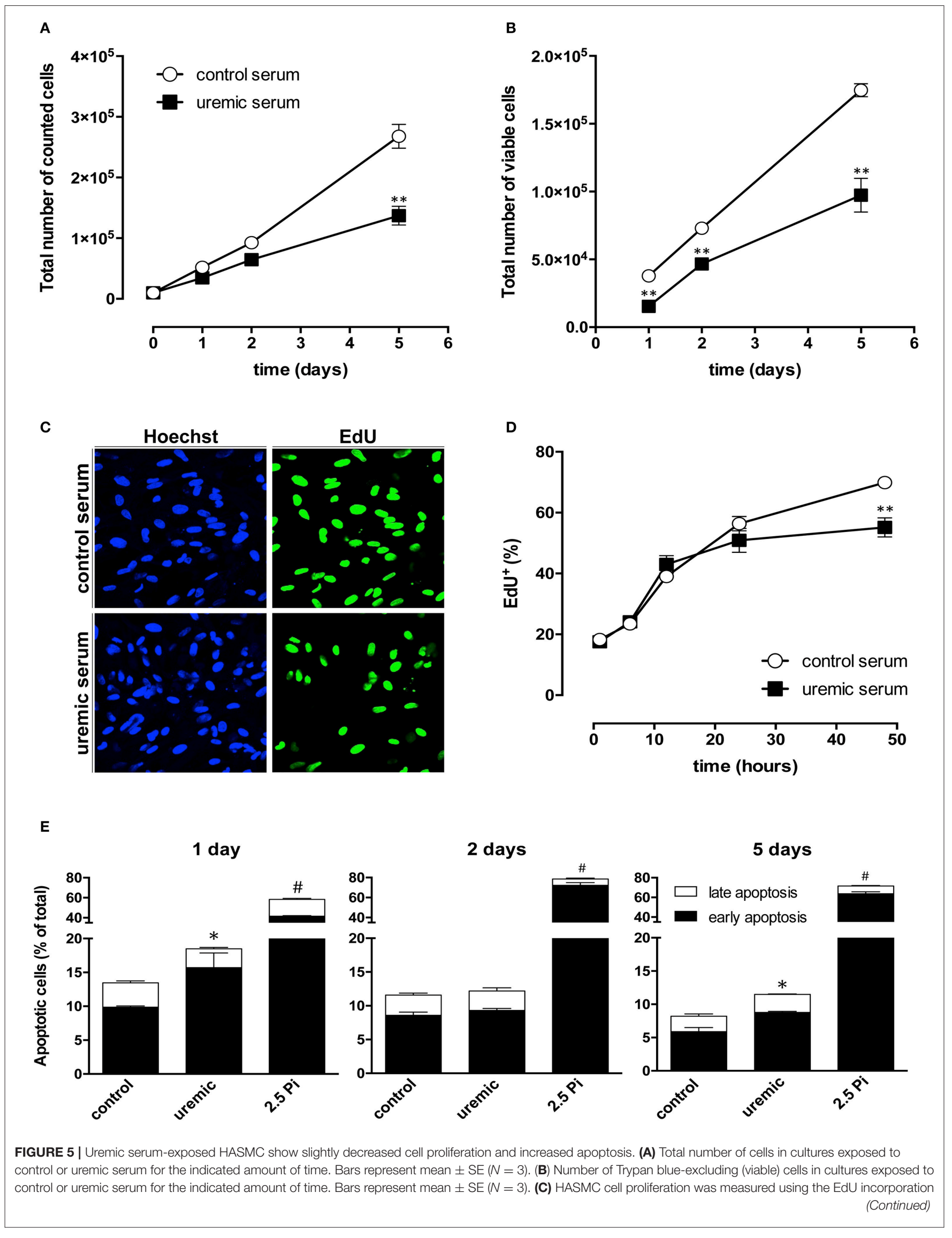


FIGURE 5 | test. Proliferating cells have green nuclei and were counterstained with Hoechst 33342. (D) Quantification shows mean \pm SE of proliferating cells ( $N=3$ ). Student's $t$-test, ${ }^{\star \star} P<0.01$. (E) Annexin $V$ apoptosis assay using flow cytometry analysis in HASMC cells cultured in DMEM supplemented with high phosphate (2,5 $\mathrm{Pi}$ ) or $20 \%$ of control or uremic serum. Data represent the percentage of apoptotic cells analyzed with annexin V-FITC/PI flow cytometry at the indicated days of treatment. Data represent the percentage of cells in early (annexin V positive, PI negative cells; black portion of each bar) or late apoptosis (positive for both markers; white portion of each bar). Values are mean $\pm \mathrm{SE}(N=3)$ and compared using one-way ANOVA followed by Tukey's multiple comparisons test; *significant vs. control serum; \# significant vs. uremic serum.

(Figures 6C,D). Treatment with cyclopiazonic acid, a known inhibitor of SERCA, increased cytosolic $\mathrm{Ca}^{2+}$ in $\sim 25 \%$ of control cells, but failed to elicit a response in cells treated with uremic serum, suggesting total depletion of intracellular $\mathrm{Ca}^{2+}$ stores (Figures 6C,E). Of note, in spite of their lack of response, uremia- treated cells are able to maintain a low cytosolic $\mathrm{Ca}^{2+}$ concentration, implying that the mechanisms that actively extrude $\mathrm{Ca}^{2+}$ are functional in those cells. Altogether, the data indicate that, in spite of the moderate changes observed in cell viability and proliferation, uremic serum treatment leads to a dramatic impairment of the functional responses of HASMC.

\section{Uremic Serum Decreases HASMC Migration}

Disease-associated phenotypic changes in VSMC not only produce an change in proliferation but also affect the capacity of the cells to migrate, a feature that has been propose to participate in the development of intimal hyperplasia (Schwartz, 1997). Therefore, we used cultured HASMC to assess whether uremia alters cell migration. To that end we used cells grown on culture dishes containing a silicon insert that creates a welldefined void. Cells were pre-treated with control or uremic serum for $48 \mathrm{~h}$ and then the silicon insert was removed and culture medium changed to serum-free conditions to prevent cell proliferation. Control cells progressively filled the void, reaching confluence after 5 days (Figure 7A). In contrast, HASMC pretreated with uremic serum displayed low migration capacity, reaching less that $20 \%$ confluence on the void space in the same time frame (Figure 7B). Surprisingly, almost all of the migration in uremic conditions took place in the first day of incubation, which suggests that cells exposed to uremic serum retain a certain degree of migration ability, but the treatment preconditions them to maintain migration rates at a very low level (Figures 7A,B).

\section{DISCUSSION}

A very common model of in vitro calcification of VSMC cultures is the use of high extracellular $\mathrm{Pi}$, which simulates the hyperphosphatemia detected in late stages of CKD (Jono et al., 2000). However, this model fails to take into account the complex metabolic and hormonal alterations present in uremic patients. In addition, a large number of published studies used VSMC obtained from bovine or rat aorta, which may produce conflicting results due to species-specific differences in the process. Therefore, we sought to examine the process of mineralization and phenotypic remodeling in primary human aortic VSMC comparing changes elicited by high extracellular $\mathrm{Pi}$ with those produced by uremic serum obtained from
CKD patients. Our results show that exposure to uremic serum induces mineralization of HASMC in culture, along with increased expression of osteogenic markers and increased alkaline phosphatase activity. The extent of mineralization is lower than that induced by $\mathrm{Pi}$, but the kinetics was similar. Surprisingly, the peak accumulation of calcium was detected at day 3 , with partial reversal afterwards. We did not investigate the mechanism behind this phenomenon, but it suggests that the use of this model is not adequate for studying chronic aspects of vascular remodeling associated with uremia, but rather short-term effects of uremic serum. This idea is reinforced by the fact that isolated cultured HASMC do not reproduce the microenvironment of the vessels, where the cells are influenced by endothelial factors, the interaction with the extracellular matrix and by hemodynamic variables.

The ability of uremic serum to induce calcification in cultured SMC was already suggested by Chen et al. who demonstrated that uremic serum supplemented with $\beta$-glycerophosphate, insulin and ascorbic acid induced calcification in bovine VSMC (Chen et al., 2006b). Our results are also in agreement with the findings of Liu Y. et al. (2016) using a similar model (HASMC treated with $10 \%$ control or uremic serum pooled from stage 5 patients). However, these studies did not compare the effect of patient serum with hyperphosphatemia. Remarkably, our results show that expression of osteochondrogenic markers and other genes involved in the development of biomineralization is fundamentally different between both stimuli. In addition, Pi induces calcification without measurable increases in alkaline phosphatase expression or activity, casting doubts on the physiological relevance of this model. Most likely, massive loss of viability and increased apoptosis in cells treated with $\mathrm{Pi}$ is probably mediating passive $\mathrm{Pi}$ precipitation. In contrast, the effect of uremic serum in cell viability and apoptosis is only moderate, although statistically significant respect to control serum. This reduction of cell viability directly correlates with a decrease in cell number, and might be explained by decreased proliferation, increased apoptosis or a combination of both mechanisms. A close look at the kinetics of uremic serum effects on the number of cells in culture reveals a decrease as soon as $24 \mathrm{~h}$ after starting the treatment, an effect that is apparent also with $\mathrm{Pi}$, correlating well with increased apoptosis within the same time frame. In comparison, Hortells et al. measured lactate dehydrogenase release as a measure of cell death induced by $\mathrm{Pi}$ in rat VSMC and found that $3 \mathrm{mM}$ Pi increased cell death only after 4 days of treatment (Hortells et al., 2015). This difference may reflect the different species source used (rat vs. human in our study) or other differences in cell culture procedure. Regarding cell proliferation, a decrease is only apparent after $48 \mathrm{~h}$ of treatment. Taken together, these results suggest that the effect 

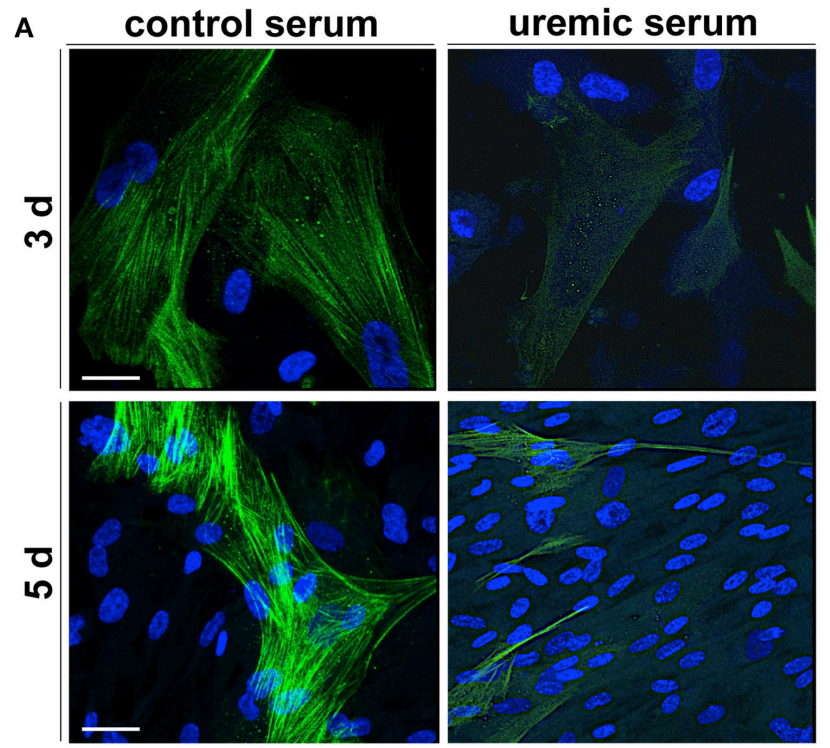

B

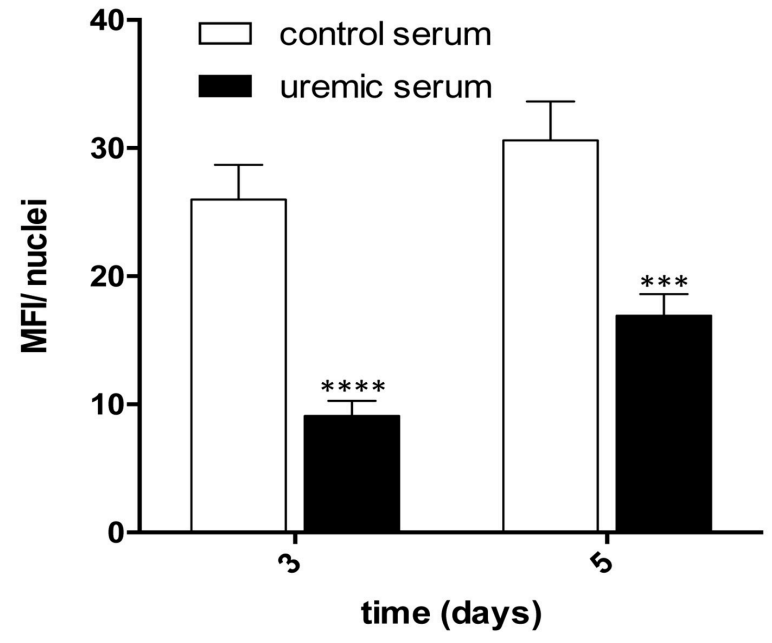

C
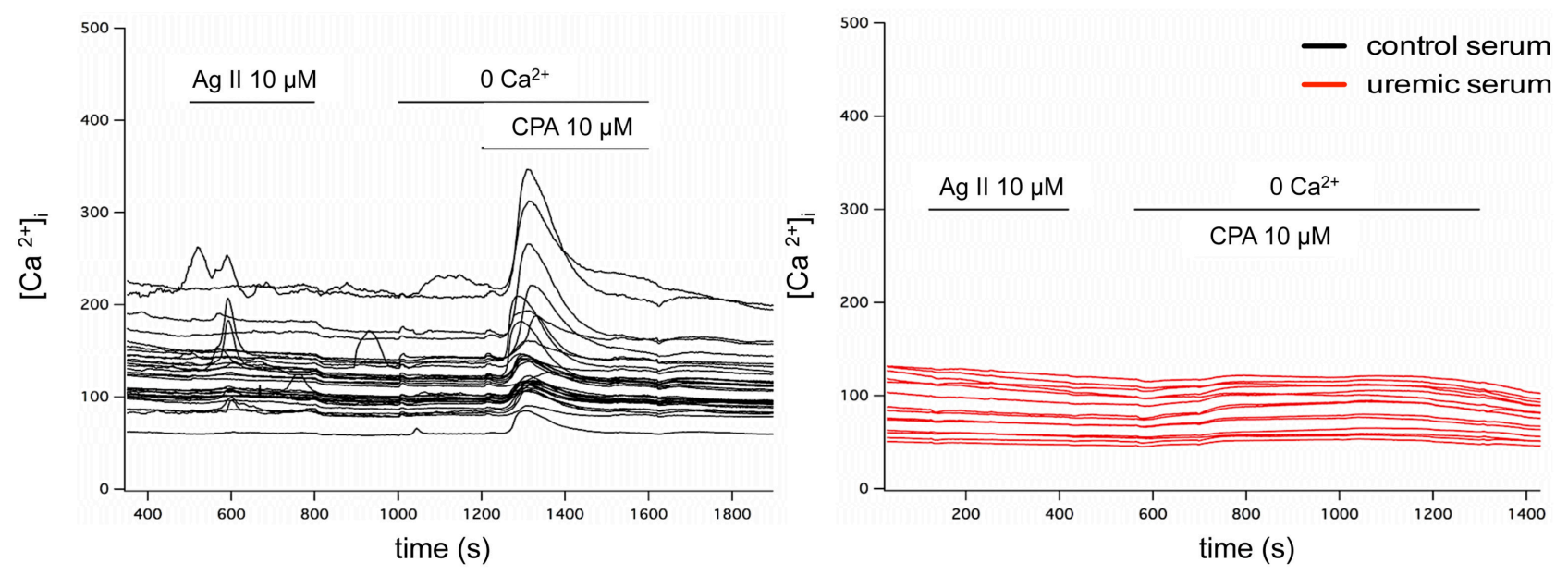

D

$\mathbf{E}$
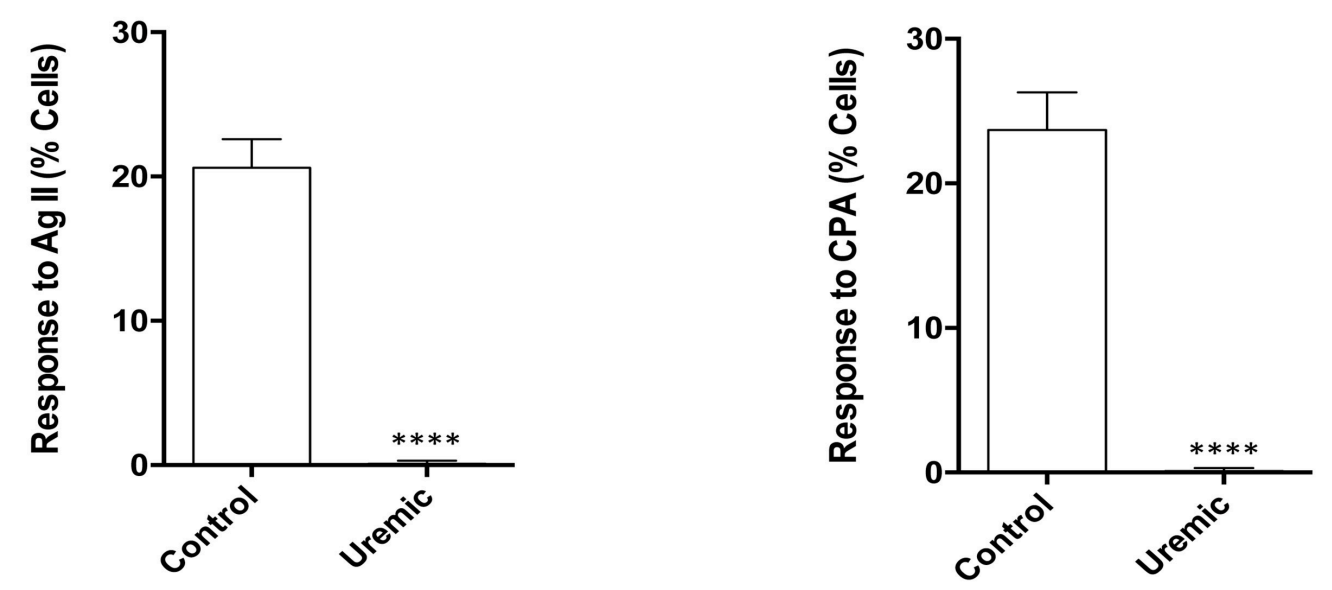

FIGURE 6 | Uremia decreases expression of contractility markers, blunts receptor-operated channel response and depletes intracellular $\mathrm{Ca}^{2+}$ stores. (A)

Representative micrographs of HASMC treated with control or uremic serum, fixed, and stained with anti- $\alpha$-SMA antibody (green). Nuclei were counterstained with 
FIGURE 6 | DAPI (blue). Bar, $28 \mu \mathrm{m}$. (B) Quantitative analysis of $\alpha$-SMA expression. Bars present average fluorescent intensity normalized by nuclei number \pm SE obtained from 15 different fields in two independent experiments. (C) Representative traces of Fluo4-loaded HASMC pre-treated with control or uremic serum, stimulated with $10 \mu \mathrm{M}$ angiotensin II (Angll) and then switched to $\mathrm{Ca}^{2+}$-free extracellular solution and stimulated with $10 \mu \mathrm{M}$ of cyclopiazonic acid (CPA). Traces represent cytosolic $\mathrm{Ca}^{2+}$ concentration (in $\mathrm{nM}$ ) over a period of 1,400 s. (D) Quantitative analysis of cells responding to Angll stimulation with a rise in cytosolic Ca $2+$ Bars represent average \pm SE. (E) Quantitative analysis of cells responding to CPA treatment. Bars represent average \pm SE. Student's $t$-test: ${ }^{\star \star \star} P<0.001$, ${ }^{\star \star \star \star} P<$ 0.0001.

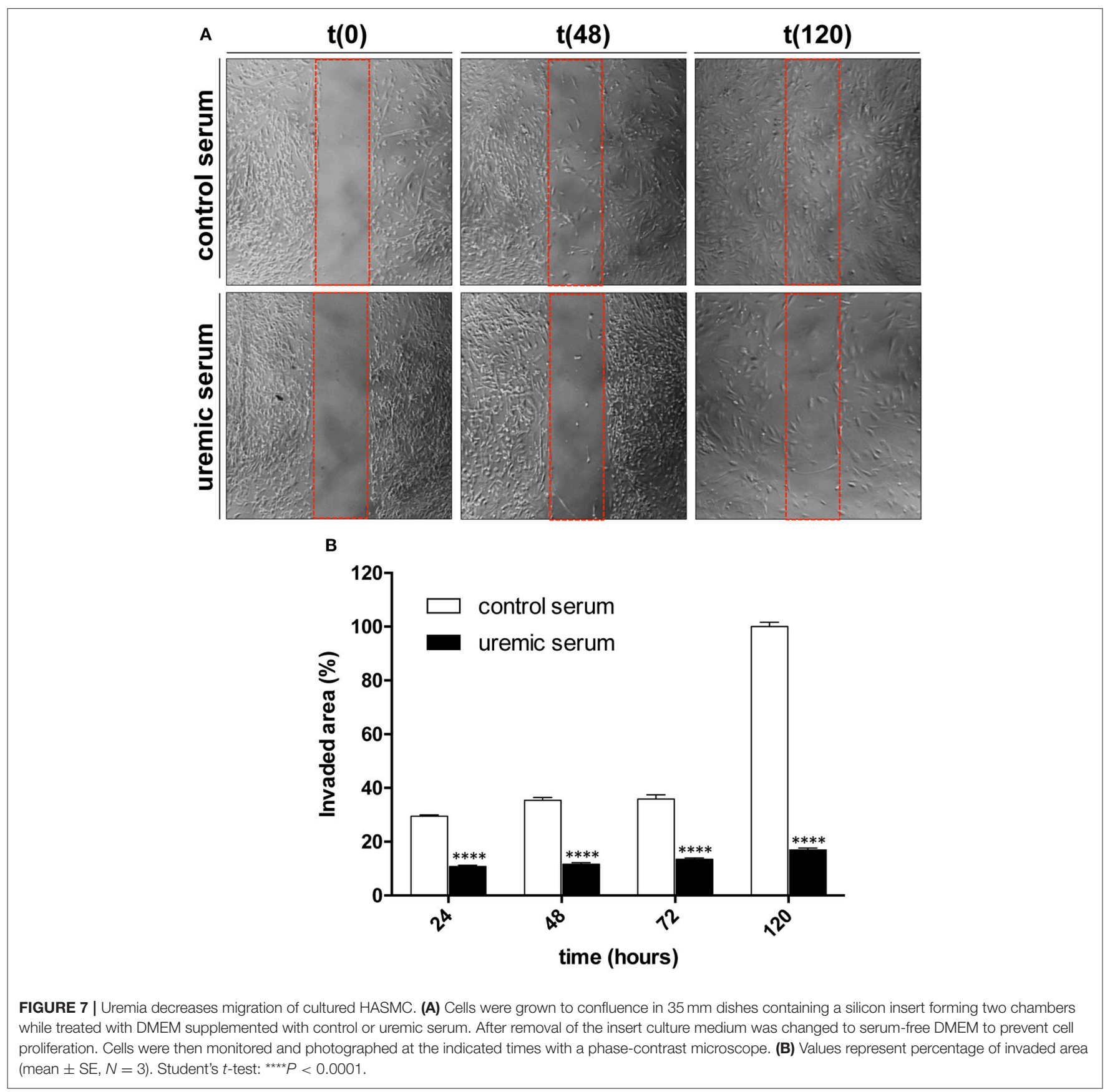

of uremic serum on the number of cells in culture is due to a combination of increased apoptosis and decreased proliferation, with varying relative importance at different times of treatment. It has been previously described that calcification is linked to increased apoptosis of VSMCs (Proudfoot et al., 2000; Shroff et al., 2008), but not in mesenchymal stem cells, where uremic serum-induced calcification was not accompanied by increased apoptosis (Kramann et al., 2011). 
In addition to proliferation, it has been proposed that altered VSMC migration contributes to intimal lesions in patients with CKD (Schwartz, 1997). Therefore, we studied VSMC migration in our model and found that, contrary to the situation in vivo, uremic serum produced a marked decrease in the capacity of VSMC to migrate. A previous study also examined the effects of uremic serum on VSMC migration and found that uremic serum inhibited PDGF-induced VSMC migration (Monroy et al., 2015). These results suggest that in vitro models of cultured VSMC are not appropriate for studying uremia-induced alterations in cell migration. This may arise from the fact that uremic serum used in these models is diluted in culture medium, but could also be due to the lack of additional signaling molecules derived from the endothelium or induced by the three-dimensional structure of the vascular wall.

In summary, our data reveals important differences in the molecular events leading to phenotypic remodeling and transdifferentiation of human VSMC exposed to Pi or uremic serum and suggests that the latter provides a more informative model for the study of vascular calcification and at least some aspects of phenotypic remodeling secondary to CKD. This model, in addition to others such as in vitro differentiation of mesenchymal stem cells to osteoblasts (Hoemann et al., 2009) should shed light on the complex process of vascular calcification associated to CKD.

\section{AUTHOR CONTRIBUTIONS}

VC-P: Performed experiments, analyzed data, interpreted results, prepared figures, and participated in drafting the manuscript.

\section{REFERENCES}

Abedin, M., Tintut, Y., and Demer, L. L. (2004). Vascular calcification: mechanisms and clinical ramifications. Arterioscler. Thromb. Vasc. Biol. 24, 1161-1170. doi: 10.1161/01.ATV.0000133194.94939.42

Amann, K., Tyralla, K., Gross, M. L., Eifert, T., Adamczak, M., and Ritz, E. (2003). Special characteristics of atherosclerosis in chronic renal failure. Clin. Nephrol. 60 (Suppl. 1), S13-S21.

Benz, K., Varga, I., Neureiter, D., Campean, V., Daniel, C., Heim, C., et al. (2017). Vascular inflammation and media calcification are already present in early stages of chronic kidney disease. Cardiovasc. Pathol. 27, 57-67. doi: 10.1016/j.carpath.2017.01.004

Boström, K., Watson, K. E., Horn, S., Wortham, C., Herman, I. M., and Demer, L. L. (1993). Bone morphogenetic protein expression in human atherosclerotic lesions. J. Clin. Invest. 91, 1800-1809 doi: 10.1172/JCI116391

Chen, N. X., Duan, D., O'Neill, K. D., and Moe, S. M. (2006a). High glucose increases the expression of Cbfal and BMP-2 and enhances the calcification of vascular smooth muscle cells. Nephrol. Dial. Trans. 21, 3435-3442. doi: $10.1093 / \mathrm{ndt} / \mathrm{gfl} 429$

Chen, N. X., Duan, D., O’Neill, K. D., Wolisi, G. O., Koczman, J. J., Laclair, R., et al. (2006b). The mechanisms of uremic serum-induced expression of bone matrix proteins in bovine vascular smooth muscle cells. Kidney Int. 70, 1046-1053. doi: 10.1038/sj.ki.5001663

Cidad, P., Miguel-Velado, E., Ruiz-McDavitt, C., Alonso, E., Jimenez-Perez, L., Asuaje, A., et al. (2015). Kv1.3 channels modulate human vascular smooth muscle cells proliferation independently of mTOR signaling pathway. Pflugers Arch. 467, 1711-1722. doi: 10.1007/s00424-014-1607-y

Coric, T., Hernandez, N. D., Alvarez de la Rosa, S. D., Wang, T., and Canessa, C. M. (2004). Expression of ENaC and serum- and glucocorticoid-induced kinase 1
PC and MP-G: Performed experiments, analyzed data and interpreted results; JD-C and EM-N: Performed determinations on serum samples and analyzed data; JL-L: Analyzed data and interpreted results of experiments; TG: Participated in the study design, analyzed data, interpreted results, and participated in drafting the manuscript; JN-G: Selected the patients, participated in the study design, interpreted results, and participated in drafting the manuscript; DA: Participated in the study design, analyzed data, interpreted results, and drafted the manuscript. All authors revised the manuscript and approved its final version.

\section{FUNDING}

This work was funded by grants BFU2016-78374-R (to DA), BFU2013-45867-R and BFU2016-75360-R (to JL-L and MP-G) from the Ministerio de Economía y Competitividad (MINECO, Spain) and PI13/01726 (to JN-G) from the Instituto de Salud Carlos III (MINECO). We acknowledge cofounding by Fondo Europeo de Desarrollo Regional (FEDER), Unión Europea ("Una forma de hacer Europa"). EM-N is recipient of a research contract from the ISCIII (FI14/00033). JD-C and JN-G are members of the ISCIII-RETIC-REDINREN (RD16/0009). TG is funded by the Ramon y Cajal Program (MINECO).

\section{ACKNOWLEDGMENTS}

We would like to thank Esperanza Alonso for excellent technical assistance.

in the rat intestinal epithelium. Am. J. Physiol. Gastrointest. Liver Physiol. 286, G663-G670. doi: 10.1152/ajpgi.00364.2003

Crouthamel, M. H., Lau, W. L., Leaf, E. M., Chavkin, N. W., Wallingford, M. C., Peterson, D. F., et al. (2013). Sodium-dependent phosphate cotransporters and phosphate-induced calcification of vascular smooth muscle cells: redundant roles for PiT-1 and PiT-2. Arterioscler. Thromb. Vasc. Biol. 33, 2625-2632. doi: 10.1161/ATVBAHA.113.302249

Demer, L. L. (2002). Vascular calcification and osteoporosis: inflammatory responses to oxidized lipids. Int. J. Epidemiol. 31, 737-741. doi: $10.1093 / \mathrm{ije} / 31.4 .737$

Giachelli, M. (2004). Vascular calcification mechanisms. J. Am. Soc. Nephrol. 15, 2959-2964. doi: 10.1097/01.ASN.0000145894.57533.C4

Hoemann, C. D., El-Gabalawy, H., and McKee, M. D. (2009). In vitro osteogenesis assays: influence of the primary cell source on alkaline phosphatase activity and mineralization. Pathol. Biol. 57, 318-323. doi: 10.1016/j.patbio.2008. 06.004

Hortells, L., Sosa, C., Millan, A., and Sorribas, V. (2015). Critical parameters of the in vitro method of vascular smooth muscle cell calcification. PLoS ONE 10:e0141751. doi: 10.1371/journal.pone.0141751

Ibels, L. S., Alfrey, A. C., Huffer, W. E., Craswell, P. W., Anderson, J. T., and Weil, R. III. (1979). Arterial calcification and pathology in uremic patients undergoing dialysis. Am. J. Med. 66, 790-796. doi: 10.1016/0002-9343(79)91118-5

Jono, S., McKee, M. D., Murry, C. E., Shioi, A., Nishizawa, Y., Mori, K., et al. (2000). Phosphate regulation of vascular smooth muscle cell calcification. Circ. Res. 87, E10-E17. doi: 10.1161/01.RES.87.7.e10

Kramann, R., Couson, S. K., Neuss, S., Kunter, U., Bovi, M., Bornemann, J., et al. (2011). Exposure to uremic serum induces a procalcific phenotype in human mesenchymal stem cells. Arterioscler. Thromb. Vasc. Biol. 31, e45-e54. doi: 10.1161/ATVBAHA.111.228601 
Levey, S., and Coresh, J. (2012). Chronic kidney disease. Lancet 379, 165-180. doi: 10.1016/S0140-6736(11)60178-5

Li, X., Yang, H.-Y., and Giachelli, C. M. (2006). Role of the sodium-dependent phosphate cotransporter, Pit-1, in vascular smooth muscle cell calcification. Circ. Res. 98, 905-912. doi: 10.1161/01.RES.0000216409.20863.e7

Lin, S., Sandig, M., and Mequanint, K. (2011). Three-dimensional topography of synthetic scaffolds induces elastin synthesis by human coronary artery smooth muscle cells. Tissue Eng. Part A. 17, 1561-1571. doi: 10.1089/ten.tea.2010.0593

Liu, C. F., Samsa, W. E., Zhou, G., and Lefebvre, V. (2016). Transcriptional control of chondrocyte specification and differentiation. Semin Cell Dev. Biol. 62, 34-49. doi: 10.1016/j.semcdb.2016.10.004

Liu, Y., Zhang, L., Ni, Z., Qian, J., and Fang, W. (2016). Calcium phosphate crystals from uremic serum promote osteogenic differentiation in human aortic smooth muscle cells. Calcif. Tissue Int. 99, 543-555. doi: 10.1007/s00223-016-0182-y

Lomashvili, K. A., Cobbs, S., Hennigar, R. A., Hardcastle, K. I., and O'Neill, W. C. (2004). Phosphate-induced vascular calcification: role of pyrophosphate and osteopontin. J. Am. Soc. Nephrol. 15, 1392-1401. doi: 10.1097/01.ASN.0000128955.83129.9C

Lu, K. C., Wu, C. C., Yen, J. F., and Liu, W. C. (2014). Vascular calcification and renal bone disorders. ScientificWorldJournal 2014:637065. doi: $10.1155 / 2014 / 637065$

Meyer, T. W., and Hostetter, T. H. (2007). Uremia. N. Engl. J. Med. 357, 1316-1325. doi: 10.1056/NEJMra071313

Mizobuchi, M., Ogata, H., Hatamura, I., Koiwa, F., Saji, F., Shiizaki, K., et al. (2006). Up-regulation of Cbfa1 and Pit-1 in calcified artery of uraemic rats with severe hyperphosphataemia and secondary hyperparathyroidism. Nephrol. Dial. Trans. 21, 911-916. doi: 10.1093/ndt/gfk008

Moe, S. M., and Chen, N. X. (2004). Pathophysiology of vascular calcification in chronic kidney disease. Circ. Res., 95, 560-567 doi: 10.1161/01.RES.0000141775.67189.98

Monroy, M. A., Fang, J., Li, S., Ferrer, L., Birkenbach, M. P., Lee, I. J., et al. (2015). Chronic kidney disease alters vascular smooth muscle cell phenotype. Front. Biosci. 20:4337. doi: 10.2741/4337

Neven, P. V., Dauwe, S., De Schutter, T., De Broe, M. E., and D'Haese, P. C. (2010). Chondrocyte rather than osteoblast conversion of vascular cells underlies medial calcification in uremic rats. Arterioscler. Thromb. Vasc. Biol. 30, 1741-1750. doi: 10.1161/ATVBAHA.110.204834

Patel, J. J., Srivastava, S., and Siow, R. C. (2016). Isolation, culture, and characterization of vascular smooth muscle cells. Methods Mol. Biol. 1430, 91-105. doi: 10.1007/978-1-4939-3628-1_6

Proudfoot, D., Skepper, J. N., Hegyi, L., Bennett, M. R., Shanahan, C. M., and Weissberg, P. L. (2000). Apoptosis regulates human vascular calcification in vitro: evidence for initiation of vascular calcification by apoptotic bodies. Circ. Res. 87, 1055-1062. doi: 10.1161/01.RES.87.11.1055

Schmittgen, T. D., and Livak, K. J. (2008). Analyzing real-time PCR data by the comparative C(T) method. Nat. Protoc. 3, 1101-1108. doi: $10.1038 /$ nprot.2008.73

Schneider, A., Rasband, W. S., and Eliceiri, K. W. (2012). NIH Image to ImageJ: 25 years of image analysis. Nat. Methods 9, 671-675. doi: 10.1038/nmeth.2089

Schwartz, S. M. (1997). Smooth muscle migration in vascular development and pathogenesis. Transpl. Immunol. 5, 255-260. doi: 10.1016/S0966-3274(97)80005-6

Schwarz, U., Buzello, M., Ritz, E., Stein, G., Raabe, G., Wiest, G., et al. (2000). Morphology of coronary atherosclerotic lesions in patients with end-stage renal failure. Nephrol. Dial. Trans. 15, 218-223. doi: 10.1093/ndt/15.2.218

Scialla, J. J., Lau, W. L., Reilly, M. P., Isakova, T., Yang, H. Y., Crouthamel, M. H., et al. (2013). Chronic renal insufficiency cohort study, Fibroblast growth factor 23 is not associated with and does not induce arterial calcification. Kidney Int. 83, 1159-1168. doi: 10.1038/ki.2013.3
Scudiero, A., Shoemaker, R. H., Paull, K. D., Monks, A., Tierney, S., Nofziger, T. H., et al. (1988). Evaluation of a soluble tetrazolium/formazan assay for cell growth and drug sensitivity in culture using human and other tumor cell lines. Cancer Res. 48, 4827-4833.

Shimizu, T., Tanaka, T., Iso, T., Kawai-Kowase, K., and Kurabayashi, M. (2012). Azelnidipine inhibits Msx2-dependent osteogenic differentiation and matrix mineralization of vascular smooth muscle cells. Int. Heart J. 53, 331-335. doi: 10.1536/ihj. 53.331

Shroff, R. C., McNair, R., Figg, N., Skepper, J. N., Schurgers, L., Gupta, A., et al. (2008). Dialysis accelerates medial vascular calcification in part by triggering smooth muscle cell apoptosis. Circulation 118, 1748-1757. doi: 10.1161/CIRCULATIONAHA.108.783738

Skalli, O., Ropraz, P., Trzeciak, A., Benzonana, G., Gillessen, D., and Gabbiani, G. (1986). A monoclonal antibody against alpha-smooth muscle actin: a new probe for smooth muscle differentiation. J. Cell Biol. 103(6 Pt 2), 2787-2796. doi: $10.1083 /$ jcb.103.6.2787

Smith, E. R. (2016). Vascular calcification in uremia: new-age concepts about an old-age problem. Methods Mol. Biol. 1397, 175-208. doi: 10.1007/978-1-4939-3353-2_13

Sonou, T., Ohya, M., Yashiro, M., Masumoto, A., Nakashima, Y., Ito, T., et al. (2015). Mineral composition of phosphate-induced calcification in a rat aortic tissue culture model. J. Atheroscler. Thromb. 22, 1197-1206. doi: $10.5551 /$ jat. 28647

Tonelli, M., and Pfeffer, M. A. (2007). Kidney disease and cardiovascular risk. Annu. Rev. Med. 58, 123-139. doi: 10.1146/annurev.med.58.071105. 111123

Tyson, K. L., Reynolds, J. L., McNair, R., Zhang, Q., Weissberg, P. L., and Shanahan, C. M. (2003). Osteo/chondrocytic transcription factors and their target genes exhibit distinct patterns of expression in human arterial calcification. Arterioscler. Thromb. Vasc. Biol. 23, 489-494. doi: 10.1161/01.ATV.0000059406.92165.31

Villa-Bellosta, R., Bogaert, Y. E., Levi, M., and Sorribas, V. (2007). Characterization of phosphate transport in rat vascular smooth muscle cells: implications for vascular calcification. Arterioscler. Thromb. Vasc. Biol. 27, 1030-1036. doi: 10.1161/ATVBAHA.106.132266

Villa-Bellosta, R., and Sorribas, V. (2009). Phosphonoformic acid prevents vascular smooth muscle cell calcification by inhibiting calciumphosphate deposition. Arterioscler. Thromb. Vasc. Biol. 29, 761-766. doi: 10.1161/ATVBAHA.108.183384

Wada, T., McKee, M. D., Steitz, S., and Giachelli, C. M. (1999). Calcification of vascular smooth muscle cell cultures: inhibition by osteopontin. Circ. Res. 84, 166-178. doi: 10.1161/01.RES. 84.2 .166

Yamada, S., and Giachelli, C. M. (2017). Vascular calcification in CKD-MBD: roles for phosphate, FGF23, and Klotho. Bone 100, 87-93. doi: 10.1016/j.bone.2016. 11.012

Conflict of Interest Statement: The authors declare that the research was conducted in the absence of any commercial or financial relationships that could be construed as a potential conflict of interest.

Copyright () 2018 Cazaña-Pérez, Cidad, Donate-Correa, Martín-Núñez, LópezLópez, Pérez-García, Giraldez, Navarro-González and Alvarez de la Rosa. This is an open-access article distributed under the terms of the Creative Commons Attribution License (CC BY). The use, distribution or reproduction in other forums is permitted, provided the original author(s) and the copyright owner are credited and that the original publication in this journal is cited, in accordance with accepted academic practice. No use, distribution or reproduction is permitted which does not comply with these terms. 